\title{
ANSELMO, AQUINO, FRANCISCO SANCHES E AS POSSÍVEIS CONTRIBUIÇÕES AO TRABALHO DE RENÈ DESCARTES
}

RESUMO: Renè Descartes é considerado um autor revolucionário, um autor que inaugurou o pensamento filosófico moderno com suas obras, as quais têm a aura do ineditismo. No entanto há autores que tiveram contribuições cronologicamente anteriores às de Descartes e que podem tê-lo influenciado e podem lançar suspeitas de que não houve da parte de Descartes tanta genialidade assim. Sabemos que Tomás de Aquino e Anselmo de Cantuária têm contribuições ontológicas em suas considerações e justificativas da existência e natureza de Deus. Já Francisco Sanches, autor português, teve seus trabalhos a respeito de epistemologia deixados de lado, mesmo sendo próximos dos trabalhos de Descartes. Este artigo pretende descrever as similaridades e diferenças entre as abordagens e verificar se é justificável afirmar que houve influência direta do trabalho destes autores às obras de Renè Descartes.

Palavras-Chave: Descartes; Influências; Gênio.

\section{ANSELMO, AQUINO, FRANCISCO SANCHES AND THE POSSIBLE CONTRIBUTIONS TO THE WORK OF RENÈ DESCARTES}

\begin{abstract}
René Descartes is considered a revolutionary author, an author who inaugurated the modern philosophical thought with his works, which have the aura of the novel. However, there are authors who had contributions chronologically prior to those of Descartes and who may have influenced him and may raise suspicions that Descartes did not have such generosity. We know that Thomas Aquinas and Anselm of Canterbury have ontological contributions in their considerations and justifications of the existence and nature of god. Already Francisco Sanches, portuguese author, had his works on epistemology left aside, even being close to the works of Descartes. This article intends to describe the similarities and differences between the approaches and to verify if it is justifiable to affirm that there was a direct influence of the work of these authors to the works of Renè Descartes.
\end{abstract}

Keywords: Descartes; Influences; Genius.

\section{INTRODUÇÃO}

O que faz de um homem um gênio? Um dos critérios é sua originalidade, o fato de ter sido o primeiro a ver o que mais ninguém viu até aquele momento em que uma

\footnotetext{
${ }^{1}$ Bacharel em Filosofia; Mestrando no PPG em Sociedade, Cultura e Fronteiras - Unioeste - Foz do Iguaçu - PR. Contato: ramosnavega@gmail.com

Programas de Pós-Graduação em Ciências Sociais e Filosofia - UNIOESTE - Rua da

Faculdade 645. Toledo - PR. CEP 85.903-000 Email: revistaalamedas@gmail.com
} 
pessoa comunica sua descoberta, ou sua invenção, ao mundo. Apesar de quase ninguém entender do que se trata a Relatividade, até mesmo muitos físicos, Albert Einstein é considerado um gênio inconteste. E ele é só um exemplo que podemos dar.

Em O Conceito de Gênio na Filosofia, Erinaldo Sales (2006) discute o conceito com mais especificidade fazendo um estudo que remonta a Platão e Aristóteles, passando a Kant, Hegel e Schopenhauer. Para Aristóteles, Erinaldo destaca que ele afirma que "o gênio se manifesta na doutrina da capacidade inventiva, não necessariamente 'louca' ou irracional do criador da arte"(p. 142). Já para Alexandre Gerard, em An Essay on Genius, o gênio cria o novo, e é assim marcado pela originalidade (apud SALES 2006, p. 143).

Para Kant as belas-artes são obra do gênio, gênio que dá regra às artes, que tem um dom natural inato. É também este gênio que dá as regras às artes que a elevam de obras simples à categoria de belas-artes. Para ele, Kant, o gênio tem como primeira propriedade de sua constituição a originalidade, daí seus produtos passam a ser exemplares e modelos de algo novo, algo que serve como regra aos demais. A imaginação e o entendimento são, para Kant, os poderes da mente de um gênio. No entanto o autor não acredita na genialidade voltada para as ciências e sim para as artes.

Hegel, no seu Curso de Estética, também fala do gênio em relação às artes, mas inclui também grandes guerreiros, reis e heróis da ciência. Mas ainda temos artistas e cientistas com condições de serem gênios em seus campos, mas nosso mundo não comporta mais reis ou grandes guerreiros com características geniais, pois a política mudou por um lado, e a guerra mudou por outro. Hegel destaca três características de um gênio, a saber: a imaginação; o talento; e a inspiração (HEGEL apud SALES 2006, p. 146).

Para Schopenhauer, segundo Sales (2006), o gênio se diferencia do homem comum no que se refere ao conforto, preenchimento e satisfação, pois o homem comum se sente absorvido e satisfeito com seu dia-a-dia, mas o gênio seria um eterno insatisfeito. Enquanto que para o homem comum o conhecimento é uma luz guia na escuridão do mundo, para o homem genial o conhecimento se apresenta como que um sol a iluminar tudo à sua volta.

Schopenhauer diz que o gênio tem uma desenvolvida capacidade de absorver e desenvolver conhecimentos, mas que tem uma vontade fraca. Além disto o gênio nos 
traz à visão tudo o que é importante, e deixa de lado tudo o que é supérfluo e inútil. O Gênio seria objetivo, claro, universal e imparcial.

Até bem pouco tempo Renè Descartes estava de pé neste panteão dos grandes gênios da humanidade, mas sua genialidade foi abalada pela possibilidade de ele não ter sido um autor tão original assim, mas apenas teve a sorte de ter tido mais visibilidade e projeção do que outros autores que vieram antes, e viram antes dele soluções que ele deu como suas.

Lembremos que, em suas Meditações sobre Filosofia Primeira (2013), Descartes afirma que seu método seria o de negar todo o conhecimento precedente para que só então pudesse encontrar certezas que fossem base de seu entendimento do mundo. Em nenhum momento de seu texto Descartes diz que seus resultados são consoantes com os de nenhum outro autor, não há notas ou referências a ninguém, a não ser ele mesmo e Deus.

Como veremos mais adiante, Descartes, entre outras coisas, utilizará de seu cogito para argumentar a respeito da existência de Deus. O mesmo fez exaustivamente Isaac Newton. O conhecemos como gênio da física e do cálculo, mas grande parte de sua vida foi empregada produzindo textos teológicos e místicos maçônicos. E Newton também protagonizou com Leibniz uma disputa pela invenção do cálculo diferencial, mas ambos chegaram às mesmas conclusões ao mesmo tempo (WESTFALL, 1995).

Este ponto da história das ciências, em especial da história do cálculo diferencial, nos dá uma pista do que pode acontecer quando algumas mentes brilhantes se põem a responder a questões universais de sua época. Pois qual é a probabilidade de algo assim acontecer? A mesma resposta, os mesmos argumentos, só diferindo da notação, e um novo ramo da matemática se abre. Pode ser isto o que houve com Descartes? Pode ele ter chegado a conclusões semelhantes sem ter sido influenciado diretamente por seus predecessores?

Charles Darwin também aparece com problemas em relação à teoria da evolução das espécies, pois Alfred Wallace chegou às mesmas conclusões, e chegou a pedir sua ajuda, sem saber do caso, para que suas descobertas fossem divulgadas (STRATHERN 2001). Neste caso a disputa pela descoberta do mecanismo da evolução não levantou dúvidas com relação à honestidade de ambos os cientistas, e, além disso, o fato de 
Wallace ter informado suas descobertas a Darwin deu coragem, um empurrão neste caso, para que Darwin editasse suas descobertas.

Mas Descartes é nosso foco aqui, e veremos os argumentos dos autores que podem ter tido influência em seu pensamento, e escreveram em relação ao que ele divulgou como seu. Então, a seguir apresentarei Anselmo de Cantuária, Tomás de Aquino e Francisco Sanches.

\section{AS MEDITAÇÕES DE DESCARTES}

A contribuição de Descartes foi nada mais, nada menos, do que inaugurar a modernidade na Filosofia. Para tal ele teve que enfrentar o pensamento hegemônico, o pensamento medieval, escolástico, que dominou toda a idade média na Europa. Para tal Descartes teve que trazer algo de novo, algo além de apenas revisar Platão e Aristóteles, como se fazia até então. Teve que ultrapassar os doutores da igreja católica, mesmo correndo o mesmo risco que correu Galileu Galilei.

$\mathrm{O}$ pensamento medieval considerava que o conhecimento provinha eminentemente dos sentidos, inclusive o conhecimento matemático, e sua filosofia expressava esta crença. Já para Descartes o conhecimento teria origens na razão humana, e seria constituído por verdades indubitáveis, e seu cogito faria o papel de base para tal afirmação. Os argumentos que Descartes constrói vão de encontro a esta crença e tentam fundamentar tal afirmação, justificando as crenças em um conhecimento possível e indubitável.

Já em relação ao ponto de vista metafísico da filosofia medieval se considerava o mundo constituído de um grande número de substâncias, o que tornava o mundo visto por esta ótica como sendo muito complicado e sujeito a mais discussões filosóficas exaustivas. Mas, para Descartes, o mundo visto por um ponto de vista metafísico seria constituído por um número pequeno de substâncias, o que deixa o estudo do mundo muito mais simples e diminui as possibilidades para discussões intermináveis.

Em relação ao ponto de vista do pensamento medieval voltado para a ciência, vemos que para os escolásticos esta tinha características qualitativas e finalistas. Os acontecimentos a serem explicados pelas ciências teriam um grande número de causas possíveis. Já para Descartes a ciência seria qualitativa e mecanicista. Esta ciência 
precisaria apenas de descrever a causa eficiente do que se queria explicar, o que acarretava uma exigência menor de um pequeno número de leis da natureza para dar conta de explicar os objetos físicos e os seres vivos.

Após termos visto as diferenças que Descartes trouxe com seu pensamento filosófico moderno à filosofia de seu tempo passemos a ver mais um ponto importante de seu pensamento, a saber, a dúvida metódica. Este nome é dado a um conjunto de argumentos cartesianos que fundamentaram suas conclusões mais a frente.

Primeiro podemos destacar o argumento referente ao fato de os sentidos serem falhos e que não há como confiarmos neles para termos um fundamento sólido onde apoiar nossas crenças em relação à realidade. Como os sentidos nos enganam algumas vezes não podemos confiar neles a ponto de termos certeza em nossas afirmações a partir de dados provenientes deles.

A seguir Descartes avança um pouco mais em sua dúvida e afirma que sequer podemos ter certeza absoluta de que estamos acordados, já que quando sonhamos acreditamos estar em estado de vigília, e quando acordamos nos damos conta de que apenas sonhávamos. Sendo assim não podemos distinguir claramente o estado de sonho do de vigília, sendo assim não podemos ter nos dados sensoriais fontes confiáveis, indubitáveis da verdade do mundo que nos cerca.

Mais a frente Descartes extrapola seu raciocínio e avança para a consideração de poderíamos estar sobre a influência de um poder externo que mudaria o que perceberíamos como verdade, alterando o resultado dos sentidos, apresentando resultados enganosos. Assim podemos achar que $2+3=5$ é correto, mas pode haver um engodo que nos leve a esta conclusão e sequer poderíamos escapar a esta ilusão. Assim, inclusive a realidade física estaria em xeque, já que este poder externo enganador poderia nos induzir a erro, o que retira a credibilidade completa de qualquer raciocínio, inclusive.

O sistema de dúvidas levantadas por Descartes tem o nome de dúvida metódica. Metódica devido ao fato de sua formulação ser feita de forma organizada e sistematicamente exposta, dúvida levantada a todo o conteúdo de crenças cujas bases não sejam indubitáveis de forma alguma. Havendo alguma sombra de dúvida a crença deve ser rechaçada. 
O sistema de dúvidas cartesiana tem o atributo de hiperbólica, pois é patentemente exagerada, pois além de duvidar de tudo o que tem motivo para duvidar, ele inventa maneiras de duvidar destas crenças.

Também chamamos este sistema de dúvidas de radical, pois como põe em xeque os dados dos sentidos e conclusões racionais deita por terra todas as crenças que se pode ter até então, derrubando os conhecimentos tradicionais acumulados em séculos de civilização.

E a característica mais útil da dúvida metódica é o atributo de ser provisória, pois não pretende ser um fim em si, mas um meio para chegar a um conhecimento básico que fundamente os demais conhecimentos humanos, o que mostra que apesar das aparências Descartes não pode ser inscrito no grupo dos céticos.

Tendo aberto mão dos sentidos como sendo fonte de bases confiáveis para as nossas crenças o autor aposta suas fichas na mente como sendo algo mais confiáveis pois apresenta certas características que a seu ver dão mais credibilidade. Para ele a mente usa de intuição, onde diretamente, e mesmo sem raciocínio, percebe algo como sendo crível, verdadeiro. Afirmações como: eu existo; eu penso; a soma dos ângulos internos em um triângulo iguala a soma de dois ângulos retos.

A dedução também seria uma fonte mais confiável de confirmação de nossas crenças, pois a partir da intuição a mente pode deduzir outras informações que já estão contidas na ação intuitiva. Assim, pode-se deduzir de definições advindas da intuição corolários possíveis.

Após destruir todo o conhecimento até então acumulado pela humanidade, Descartes parte para a construção de um conhecimento sólido onde possa ancorar suas crenças. A esta primeira verdade indubitável deu-se o nome de cogito. A afirmação inicial do cogito é a proveniente do fato de que a dúvida carece de que o ser a duvidar precise existir, e daí segue a afirmação "cogito, ergo sum" (penso, logo existo).

A partir deste ponto, o autor teria a seu dispor um ponto inicial seguro para poder deduzir outras afirmações. Se é indubitável que para se duvidar tem-se que existir, e esta é a primeira verdade indubitável, pode-se reconstruir todos os demais conhecimentos anteriormente destruídos pela dúvida.

Se o homem pode ser definido, então, como ser pensante, como substância pensante, pode-se afirmar que ele tem existência independente e que o pensamento é sua 
propriedade principal, assim ele pode duvidar, entender, negar, afirmar, desejar, criar com o pensamento, sentir, conjecturar, etc.

Outra característica marcante deste cogito é o fato de ele ser distinto do corpo, e poder ser melhor conhecido que aquele. Enquanto posso duvidar da realidade de meu corpo, não posso duvidar da existência de meus pensamentos. Este conhecimento, é ao ver de Descartes, claro e distinto. Não existe possibilidade de erro ou ilusão quanto a estas afirmações, e estas características não podem ser confundidas com outras quaisquer.

Daí, o autor passou a ter um critério de verdade indubitável, pois todas as crenças que possam ser deduzidas da mesma forma que esta, a que ele teve acesso, com seu "penso, logo existo", serão verdades claras e distintas, serão verdades indubitáveis.

Estes conhecimentos serão, assim, reconhecidos como verdades pela intuição, não passando pela armadilha da dúvida hiperbólica cartesiana, e imediatamente a razão a reconhecerá sem a ajuda de raciocínios ou inferências de espécie alguma.

Deste ponto privilegiado, Descartes faz as afirmações às quais queria chegar desde o início, e que inspiraram suas meditações até aqui, a saber: o cogito encerra em si a ideia da existência de deus, sendo este, para ele, uma ideia clara e distinta em sua mente, já que a ideia de Deus tem que ter uma causa e aparece intuitivamente em seus pensamentos.

Para o autor das Meditações, tem de haver tanta realidade na causa de uma ideia de Deus quanto na existência em mente da própria ideia. E se tal ideia, a de Deus, viesse do cogito a causa seria mais real do que o efeito, do que a ideia. Assim, o cogito não pode ser a origem da ideia de Deus, e ele conclui que Deus é a origem da existência da ideia de Deus.

Seguremos estudando a contribuição de alguns pensadores predecessores de Descartes, que podem ter contribuído com seus argumentos estudados acima.

\section{ANSELMO DE CANTUÁRIA}

Anselmo, ou Santo Anselmo foi filósofo, teólogo, prior (1063) e abade (1078) de Bec, na Normandia, França, e, por último, arcebispo de Cantuária, Inglaterra, (nasceu em Aosta, na atual Itália, em 1033/1034, faleceu no mosteiro de Bec, em 1109), "uma 
das figuras mais humanas e atraentes de toda a Idade Média, que o agraciou com o título de Doutor Magnífico" (FREITAS, 2004).

Nas palavras do mesmo Freitas, 2004:

Toda a sua obra reflete o esforço do crente que procura descobrir o rosto de Deus tanto no mistério da sua vida íntima como nas criaturas, que são sua imagem ou ainda nos acontecimentos providenciais da história. A palavra de Deus é assumida como fonte primeira e critério último de toda a especulação anselmiana.

Em sua obra, por diversas vezes e em diversos lugares, nos "deparamos com o princípio do crer para compreender e do compreender para mais e melhor amar". Este ardor de contemplação mística explica a procura dos mistérios da fé, mas não a procura de razões de simples conveniência, mas de "razões necessárias". (FREITAS, 2004).

Como parece que nada vem do nada, no Monologion Santo Anselmo segue de perto o De Trinitate de Santo Agostinho. Baseado no princípio de causalidade aplicado à multiplicidade dos seres e aos graus de bondade, Santo Anselmo conclui: a) a existência de um Bem supremo, fonte única de todos os bens; b) a existência de um Ser soberano que, existindo por si, produz todos os outros seres; c) a existência de um Ser absolutamente perfeito que confere aos seres imperfeitos a sua relativa perfeição. Estes três atributos ou perfeições convergem num único e mesmo Ser absoluto e necessário, que é Deus. (FREITAS, 2004).

No Monologion, a preocupação principal de Anselmo não girava em torno da tentativa de provar a existência de Deus, mas falara a respeito de sua natureza. E para tal o autor em foco usou de muitos argumentos. Para seu próximo livro Anselmo queria dispor de um argumento único, autoevidente e definitivo para, desta vez, provar a existência de Deus. E é o que ele julga ter feito em sua segunda obra, o Proslogion (ARAÚJO, 2013).

Aqui vemos um laço com a tentativa de Descartes pois ambos, Descartes e Anselmo, queriam bases sólidas e um conhecimento autoevidente para justificar suas crenças, e dar bases aos demais crentes da existência indubitável de Deus. Anselmo utiliza para tal um argumento ontológico, e Descartes utilizará a dúvida, um aparente ceticismo, para obter seus argumentos. 
No entanto, a exemplo do que aconteceu com Descartes, a complexidade destes três argumentos não satisfaz plenamente Santo Anselmo, que continua a ensaiar uma demonstração que não se baseie em qualquer outra e que seja suficiente para estabelecer ao mesmo tempo a existência de Deus, a sua natureza... e, enfim, o conjunto de todas as verdades antecipadas pela fé. (ARAÚJO, 2013).

Como já havia se tornado um clássico, para todos os filósofos da época de Descartes, seria impossível que ele não conhecesse os argumentos de Anselmo, quando tem ideias semelhantes para argumentar em seu trabalho mais famoso.

Aqui Freitas, 2004, encerra seu texto com as seguintes palavras:

\begin{abstract}
É assim que no Proslogion, a obra que mais o celebrizou no mundo filosófico, se formula uma demonstração baseada na presença imediata e irrecusável em toda a inteligência humana da ideia de um ser tão perfeito que não é possível pensar outro mais perfeito do que ele. Um tal ser só pode ser pensado sem contradição se existir simultaneamente no espírito e na realidade. A natureza da sua perfeição é tal que ela mesma contém a razão da sua existência. A todas as tentativas de refutação deste argumento, conhecido por argumento a priori ou ontológico (Kant), produzidas ao longo da história e fundamentalmente baseadas numa alegada passagem ilegítima do plano das ideias para o plano da realidade.
\end{abstract}

Mais tarde, como veremos mais adiante, Descartes usará semelhante artifício para justificar a existência de Deus, usando o argumento de não poder haver algo maior, em termos de perfeição do que Deus.

John Cottingham (1995) afirma que Descartes estava chateado com o tempo que estava levando em seu texto Regulae para descrever seu método e que queria algo mais simples e evidente, chamo a atenção aqui para a preocupação semelhante que levou Anselmo de Cantuária a justificar a existência de deus com o mínimo de argumentos o possível, mais um ponto de contato entre os dois autores.

\title{
TOMÁS DE AQUINO (1225-1274)
}

Tomás de Aquino nasceu em Roccasecca em 1225, no condado de Aquino. Foi um frade da Ordem dos Pregadores (Dominicanos) cujas obras tiveram enorme influência na teologia e na filosofia, principalmente na tradição conhecida como Escolástica, sendo um de seus maiores expoentes. Tomás de Aquino morreu em 7 de 
março de 1274. Pelo alcance e extensão de sua obra ele pode ser considerado como o maior filósofo dentre os escolásticos.

Tomás não tem apenas interesse histórico para a filosofia, mas sua influência continua viva na igreja e em diversos estabelecimentos educacionais mantidos por católicos, sendo tão presente, segundo Bertrand Russell (1957), como " Platão, Aristóteles, Kant e Hegel — maior, com efeito, que a destes dois últimos".

Russell nos dá mais detalhes a respeito da vida de Tomás de Aquino:

Santo Tomás era filho do conde de Aquino, cujo castelo, no reino de Nápodes, se achava perto de Monte Cassino, onde começou a educação do " doutor angélico" . Esteve seis anos na Universidade de Nápoles, de Frederico II; tornouse depois dominicano e foi para Colônia, a fim de estudar sob a direção de Alberto Magno, que era o aristotélico mais eminente entre os filósofos da época (...) estavam em dificuldades com as autoridades universitárias, suspeitas de simpatia herética pelos partidários de Averroés, que constituíam um grupo poderoso na universidade. Os averroístas afirmavam, baseados em sua interpretação de Aristóteles, que a alma, enquanto é individual, não é imortal; a imortalidade pertence apenas ao intelecto, que é impessoal, e idêntico em diferentes seres intelectuais. (RUSSELL, 1957, p. 396).

Uma de suas maiores façanhas se inscreve no fato de ele, Tomás, ter convencido a igreja a preferir o sistema aristotélico ao sistema platônico de filosofia, trocando o segundo pelo primeiro como base da filosofia cristã, persuadindo assim que cristãos e averroístas haviam interpretado mal a filosofia de Aristóteles.

Em contraposição à proposta de Anselmo, Tomás de Aquino parte para a análise da diferença entre existência e essência. Indo contra intuitivamente Tomás de Aquino parte da observação das essências mais complexas, chamadas compostas, passando pelas mais simples e chegando à simplíssima, que identifica a Deus.

O primeiro passo consiste em provar a existência de Deus. Alguns julgam que isto não é necessário, já que a existência de Deus (dizem) é evidente por si mesma. Se conhecêssemos a essência de Deus, isto seria certo, já que (como mais tarde se prova), em Deus, a essência e a existência são uma única coisa. (...) Mas não conhecemos sua essência senão de maneira muito imperfeita. Os sábios sabem mais da Sua essência que os ignorantes, e os anjos a conhecem mais que ambos; mas nenhuma criatura sabe o suficiente para poder deduzir a existência de Deus da Sua essência. Sobre esta base, rejeita-se o argumento ontológico. (...) A existência de Deus é provada, como em Aristóteles, pelo argumento do motor imóvel. Há coisas que são somente movidas, e outras que tanto se movem como são movidas. Tudo que é movido é movido por algo e, já que é impossível uma regressão eterna, 
devemos chegar a alguma parte em que algo move as outras coisas sem ser movido. Este motor imóvel é Deus. (RUSSELL, 1957, p. 398).

Para Tomás de Aquino, as substâncias compostas têm sua existência separadas, distintas, de sua essência, o mesmo se dando com as substâncias simples. Daí ele conclui que tal característica lhes foi dada por alguém.

\begin{abstract}
Ora, não pode acontecer que o ser ou existência seja causado pela própria forma, ou pela quiididade da coisa. Estamos falando, naturalmente, de causa eficiente, pois neste caso, uma coisa seria causa de si mesma, e uma coisa se produziria a si mesma, o que é impossível. Por conseguinte, é necessário que toda coisa cujo ser difere da sua natureza tenha sua existência de outra. (TOMÁS DE AQUINO, apud ARAUJO 2013).
\end{abstract}

\title{
FRANCISCO SANCHES (1552-1623)
}

Filho de cristãos novos, ou seja, judeus convertidos sob pressão religiosa da época em foco neste trabalho, de origem espanhola, Sanches nasceu em Tuy ou Braga, Portugal. Ainda devido a perseguições a família mudou-se para Bordeaux, França. Filósofo e médico, Francisco lecionou em Toulose.

Embora nos interessemos pelo Sanches filósofo ele produziu mais no campo da medicina, mas sua obra que nos interessa é o De multum nobili et prima universali scientia: quod nihil scitur (1581) (O mui nobre e primeiro conhecimento universal: que nada se pode saber).

Em sua obra mais famosa Sanches discute a respeito do conhecimento a partir de um ponto de vista eminentemente cético. Afirma que não se pode saber nada sobre a natureza das coisas, e por esta causa não podemos demonstrar nada através de alguma definição:

Sanches inicia a obra afirmando que nem sequer sabe que nada sabe, que isto não passa de uma conjetura que ele faz sobre si e sobre os demais seres humanos. Este princípio constitui a sua bandeira e dele se segue a proposição nada se sabe. Se Sanches soubesse prová-la, concluiria com razão que nada se sabe. Se não soubesse prová-la, seria melhor ainda, pois é justamente isto que afirma. (PINTO, 2010, p. 116) 
Neste ponto Sanches segue os passos de Sócrates, que afirmava que nada sabia, mas vai além dele, pois para Sanches nem sabemos que nada sabemos, apenas supomos saber. Isto nos deixa num beco sem saída de ceticismo. Para Sanches a busca do conhecimento sempre resultará num regresso infinito a um conhecimento prévio que venha a validar o que se afirma em cada parte de um argumento a respeito da coisa que se pretende conhecida.

Sanches afirma que se a ciência se baseia no conhecimento das coisas levandose em conta suas causas, nós teríamos de buscar depois as causas dessas mesmas causas, e depois as causas das novas causas, levando novamente a um regresso ad infinitum.

A seguir Sanches define do que precisamos para concluirmos que nada sabemos a respeito de nada. Ele assinala que precisamos observar o objeto do qual se quer afirmar algo; depois o sujeito que deseja fazer tal afirmação; e após devemos considerar o próprio conhecimento em si.

Além disso o autor afirma que como as coisas a serem conhecidas parecem ser infinitas, e como algumas parecem ser eternas, outras são geradas constantemente, outras se corrompem constantemente e outras, a seu turno, mudam constantemente, a dificuldade de se ter uma ciência que abarque tudo, que não seja por si só fragmentária, é impossível, e este fato atesta nossa mais profunda ignorância a respeito do mundo que nos cerca. Estamos nas palavras do autor como que em um labirinto e nosso destino é o de encararmos um Minotauro ao final da jornada.

Para assinalar nossas dificuldades Sanches nos lembra que só podemos utilizar nossos sentidos para termos noção do mundo, mas estes sentidos, em seu entender, só nos trazem a parte mais vil do mundo, apenas seus acidentes, nada trazendo de profundo ou espiritual.

Já para que o sujeito que busca o conhecimento pudesse vir a conhecer a verdade ele deveria conhecer sua alma, mas esta não é sua criação, e só a poderia conhecer se conhecesse a Deus. Aqui voltamos a encontrar o objetivo de Anselmo, Tomás de Aquino e de Descartes, a argumentação na direção de provar a existência de Deus, o que mostra o tema preferido na filosofia da escolástica e no início da modernidade.

Quanto ao conhecimento do conhecimento em si, da ciência da ciência em si, Sanches volta a tocar em argumentos próximos a que Descartes usará mais tarde, pois diferenciando conhecimentos perfeitos e imperfeitos, deixa os primeiros a Deus e os 
segundos aos homens. Assim "o conhecimento perfeitíssimo exige um corpo perfeitíssimo, unido a uma razão perfeitíssima.". (PINTO, 2010, pp. 121-122).

Apesar de toda a qualidade de argumentos e pela fama que ganhou por suas obras em filosofia e medicina, e de ter apresentado várias das características comuns dos pensadores modernos de sua época, Pinto (2010) aponta que "Sanches representa o ponto máximo de modernismo a que um pensador ibérico da época poderia chegar sem comprometer sua visão de mundo católica."

Pinto afirma que o autor Joaquim de Carvalho cita o trabalho de um terceiro autor, que percebeu as relações do trabalho de Francisco Sanches com o trabalho de Renè Descartes. Este texto é de autoria de Pierre Casac, num escrito inédito conservado no Institut Catholique de Toulouse e intitulado L'Espagnol Don Francisco Sanchez, dit le Sceptique, Professeur Royal de hilosophie et de Médécine à l'Université de Toulouse(1550-1623). Contribution à l'histoire de sa vie. Nele Casac suspeita que Descartes teve conhecimento da obra de Sanches, Quod nihil scitur, sendo então por ele influenciado.

Uma segunda referência feita por Joaquim de Carvalho é de autoria de Ioaquín Iriarte, em sua tese Kartesischer oder Sanchezischer Zweifel? Ein kritischer und philosophischer Vergleich zwischen dem Cartesischen "Discours de la Méthode” und dem Sanchezischen "Quod nihil scitur" (1935). Iriarte, neste texto, compara os textos de Sanches e Descartes mencionados no título, "sugerindo uma influência do primeiro na problemática, na estrutura e na marcha do pensamento do segundo".

Carvalho, avaliando a questão referente à dúvida no trabalho tanto de Descartes quanto de Sanches, pensa ser estas aproximações citadas nos parágrafos acima, apenas possibilidades, e não fato. Para ele, Carvalho, ambos os autores só teriam em comum a busca de uma fundamentação para a ciência das coisas do mundo, e partem da dúvida radical para fundamentar a mesma. A distinção entre os dois autores a respeito destas características reside no fato de Descartes superar a dúvida através do cogito ergo sun, e Sanches mantém a dúvida utilizando-se da característica do imediatismo dos dados sensoriais. Assim, Descartes passa para uma certeza baseada num idealismo, mas Sanches permanece no patamar dos sentidos e lida apenas com o que eles lhe fornecem, e do qual duvida. 
Conclui-se, então, que embora ambos, Descartes e Sanches, partam do mesmo ponto, a dúvida, ambos chegam a conclusões diferentes. O que mostra que se Descartes se baseou em Sanches ele não parou antes de chegar a um fato novo, o que nos mostra afinal um ponto positivo importante para este autor.

Para Popkin (apud PINTO 2010) Sanches aceita sua postura cética como natural e dispões do juízo e da observação para dar conta das limitações dos sentidos, e nisso também se diferencia de Descartes, que apresentou um método para combater o ceticismo.

Mas não confundamos o ceticismo de Sanches com o dos pirronistas, por exemplo, já que Sanches tem o pano de fundo religioso, influenciado pelo catolicismo, para formar suas ideias. Ele não busca nada além de desacreditar os homens em sua busca por conhecimento, e pretende sim prepará-los para a redenção de seus pecados perante Deus.

Procurando na bibliografia que envolve o nome de Descartes e de Francisco Sanches podemos encontrar no livro Dicionário Descartes, de John Cottingham, na página 119, o verbete intitulado Método. Nele vemos dados muito interessantes a respeito de Descartes e de como se faziam os textos em sua época. Em relação ao método, o autor de Dicionário Descartes afirma que em sua época, início da modernidade, era muito comum os autores afirmarem que estavam revolucionando os métodos científicos e de pesquisa, assim como afirmou-se em relação a Descartes. Para Cottingham (1995) no século XVI e início do século XVII havia bastante deste tipo de afirmação e deste tipo de autores.

Cottingham também afirma que inclusive o tom adotado por Descartes no início de suas meditações é "antecipado, com um admirável nível de detalhes, na obra de Francisco Sanches" (COTTINGHAM, 1955, p 119). Por exemplo Sanches começa sua obra afirmando que iria recolher-se a si mesmo e que poria tudo em dúvida e que seria este o verdadeiro modo de vir a conhecer algo.

Para Sanches dever-se-ia abrir mão dos conhecimentos provenientes de outros homens como nós, como veio a se referir a Aristóteles. Assim, Sanches abre mão de chamar a autoridade dos antigos autores para dar credibilidade às suas ideias. Deixaria de simplesmente copiar e passaria a tentar produzir conhecimentos por si próprio. 
Francisco Sanches, conforme o texto de Cottingham, abriria mão do que haviam afirmado os antigos mestres da filosofia e passaria a confiar na natureza como guia de suas investigações. Tal afirmação foi um avanço para um português daquela época, porque como afirma Paulo Roberto Margutti Pinto, em sua obra As ideias filosóficas de Francisco Sanches, os autores ibéricos, e em especial os autores portugueses, tinham, por suas características históricas e culturais, um afastamento das novidades da modernidade e tudo o que ela trazia de novo para os demais países europeus da época em questão.

Ainda para reforçar nossa intuição de que nada vem do nada, o próprio lema de Francisco Sanches, "Sigo apenas a natureza", parece se referir a um texto de Joannes Vives, De Disciplines (1531), obra que Cottingham afirma que provavelmente o próprio Sanches conhecia.

\section{RENÈ DESCARTES (1596-1650)}

Descartes deu novo fôlego à já estagnada filosofia do final do século XVI. A escolástica estava esgotada devido à sua ligação com a igreja. As ameaças da inquisição desestimulavam quem tentasse trazer algo de novo à filosofia. Platão e Aristóteles foram exauridos pelos séculos de comentários. Mesmo após um século de Renascimento a filosofia estava calcada aos pés da religião.

$\mathrm{O}$ advento das ideias Cartesianas revolucionou o quadro de então e inauguraram a modernidade na filosofia ocidental, refletindo, finalmente, o espírito de sua época.

Numa estória de vida solitária, onde não havia para Descartes qualquer certeza, a única garantia de um vínculo real era a matemática, e foi nela que ele se refugiou por boa parte da vida, buscando em seu intelecto as certezas necessárias para existir e compreender o mundo que o cercava.

Assim como Sócrates, e como vimos antes também com Francisco Sanches, Descartes estava convencido de sua ignorância em relação à realidade. Até a matemática revelava suas limitações se ele quisesse aplica-la na prática. A outra certeza que abrigava em si era a existência de Deus.

O primeiro ponto que Descartes ataca em suas Meditações diz respeito aos sentidos. Para ele, tanto quanto para Sanches, os sentidos são falhos e constantemente 
nos levam a erro, e não é recomendável confiar nos dados que eles nos apresentam. Este é um argumento eminentemente cético, traz a desconfiança no leitor de que Descartes faria um texto em consonância com esta vertente de argumentos.

Mais a frente Descartes avança mais um pouco apresentando a dúvida em relação ao que a mente nos traz de verdadeiro, pois cita o sono, e o sonho, como fontes de ilusões, já que não temos noção de estarmos sonhando, e acreditamos estarmos acordados, mesmo quando o que sonhamos não faz sentido. Sendo assim mais uma fonte de engano, pois não temos certeza de que estamos acordados neste momento ou não.

\begin{abstract}
Como se eu não fosse um homem, acostumado a dormir à noite e sentir nos sonos todas essas mesmas coisas, e até menos verossímeis, do que eles em sua vigília! Em verdade, com que freqüência o sono noturno não me persuadiu dessas coisas usuais, isto é, que estava aqui, vestindo esta roupa, sentado junto ao fogo, quando estava, porém, nu, deitado entre as cobertas! Agora, no entanto, estou certamente de olhos despertos e vejo este papel, e esta cabeça que movimento não está dormindo, e é de propósito, ciente disso, que estendo e sinto esta mão, coisas que não ocorreriam de modo tão distinto a quem dormisse. Mas, pensando nisto cuidadosamente*, como não recordar que fui iludido nos sonos por pensamentos semelhantes, em outras ocasiões! $\mathrm{E}$, quando penso mais atentamente, vejo do modo mais manifesto que a vigília nunca pode ser distinguida do sono por indícios certos, fico estupefato e esse mesmo estupor quase me confirma na opinião de que estou dormindo. (...) Sonhemos, portanto, e que aquelas coisas particulares - que abrimos os olhos, mexemos a cabeça, estendemos a mão e coisas semelhantes* — não são verdadeiras e talvez não tenhamos também estas mãos, nem este corpo todo. (DESCARTES, 2013, p. 25).
\end{abstract}

É curioso, neste momento, lembrarmos que na biografia de Descartes há referência a três sonhos, que teve em campanha, na Alemanha, enquanto servia como militar, e que o impulsionaram a escrever a respeito dos temas que seriam os mais importantes de sua filosofia futura. E mais tarde ele utiliza os sonhos como argumento de desconfiança e dúvida.

Devemos prestar atenção no fato de que para Descartes os sentidos nos enganam algumas vezes, já os sonhos nos enganam sempre, sendo fontes de ilusão permanente. Aqui ele vai além dos argumentos de Sanches, que cita apenas os dados dos sentidos como sendo insuficientes.

A partir dos argumentos da dúvida dos sentidos, e depois com o argumento dos sonhos, descartes vai mais longe um pouco. Ele passa a duvidar de algo que vai além e 
que a princípio independe dos sentidos, a saber, a lógica matemática e a geometria. Descartes apresenta o argumento conhecido como sendo do gênio maligno, ou do Deus enganador.

\begin{abstract}
Todavia, está gravada no meu espírito uma velha crença, segundo a qual existe um Deus que pode tudo e pelo qual fui criado tal como existo. Mas quem me garante que ele não procedeu de modo que não houvesse nem terra, nem céu, nem corpos extensos, nem figura, nem grandeza, nem lugar, e que, no entanto, tudo isto me parecesse existir tal como agora? E mais ainda, assim como concluo que os outros se enganam algumas vezes naquilo que pensam saber com absoluta perfeição, também eu me podia enganar todas as vezes que somasse dois e três ou contasse os lados de um quadrado (Meditações sobre a Filosofia Primeira, pp. 110-111.).
\end{abstract}

O que importa aqui é o fato de Descartes apresentar com este argumento duas proposições importantes na construção de seu pensamento, a saber, o de que o mundo material, externo a nós, ao qual conhecemos apenas utilizando-nos dos sentidos pode ser ilusório, mas também, e o mais importante aqui, que a lógica de nossos pensamentos, inclusive os matemáticos, podem ser fruto de ilusão.

Aqui então chegamos onde Descartes nos queria colocar, e chegamos muito mais longe que Anselmo, Tomás de Aquino e Francisco Sanches jamais alcançaram. As dúvidas abarcaram em sequência não só os dados sensoriais, mas também se estamos acordados para percebê-los, e se não estamos também enganados em nossas conclusões lógicas.

Com estes argumentos Descartes pretende demolir o edifício conceitual precedente, deixando um solo aberto para novas ideias. Esta parte do pensamento de nosso autor é chamado de parte destrutiva, e a respeito da dúvida podemos destacar estas características:

- metódica, porque procede de forma organizada e sistemática à investigação das nossas crenças, baseada no princípio que só é verdadeiro aquilo de que não houver nenhuma razão para duvidar;

- hiperbólica, ou exagerada, porque considera como falso aquilo de que há razões para duvidar e inventa razões para duvidar, como os argumentos dos sonhos e do Deus enganador;

- radical, porque põe em causa os princípios ou fundamentos do pensamento tradicional (os sentidos e a razão) e incide, em princípio, sobre todas as nossas crenças; 
- provisória, porque não é um fim em si mesmo, como a dúvida cética, mas um meio para alcançar a primeira certeza (Fonte: Nunes, 2017).

Descartes passa a seguir, após reduzir tudo a dúvidas, a procurar alguma certeza, o que se configura na parte construtiva de seu trabalho. Sabemos que ele chega à conclusão final de que pode apenas ter certeza de que está pensando, e de que este pensamento é indubitável.

Mas o que sou eu então? Uma coisa pensante. O que quer isto dizer? Quer dizer: uma coisa que duvida, que compreende, que afirma, que nega, que quer, que não quer, que também imagina, e que sente. (Meditações sobre a Filosofia Primeira, p. 124.)

Descartes usa agora de seu "penso, logo existo" como ponto de apoio para suas novas conclusões a respeito das certezas que pode ter em relação ao conhecimento. Para ele as ideias que estejam em sua mente e pareçam claras e distintas serão indubitáveis. Daí verificamos a posição fundacionalista cartesiana em relação ao conhecimento. Ele buscou, e concluiu encontrar este conhecimento fundamental onde construiria um novo edifício conceitual, agora com firmes alicerces.

A seguir, Descartes afirma que intuição e dedução são formas de conhecimentos seguros. Sendo que as ideias claras e distintas surgidas na mente são intuitivas, já as derivadas destas são dedutivas.

O racionalismo cartesiano se mostra mais estruturado em seu cogito. Nele estão concentradas as certezas de seu trabalho. Ele mostra a vitória da razão sobre os sentidos. Vejamos as características do cogito a seguir:

\section{COGITO}

Primeira indubitável

Ponto de partida do saber

Substância pensante

Distinto do corpo e melhor Posso ter a certeza da minha existência enquanto alma, mas posso conhecido do que ele

Claro e distinto verdade A primeira crença que resiste à dúvida: para que eu possa duvidar tenho de existir.

Como primeira verdade indubitável, vai ser a partir dela que a reconstrução do saber se vai fazer.

Existe por si próprio e tem como propriedade essencial o pensamento (duvidar, compreender, afirmar, negar, querer, imaginar, sentir). 


\title{
COGITO
}

Critério de verdade

Conhecido por intuição

(Fonte: Nunes, 2017) com nenhuma outra coisa.

Todas as crenças que, como o eu penso, logo existo, são claras e distintas são verdades indubitáveis.

Conhecido imediatamente como verdadeiro pela razão, sem o recurso a inferências ou raciocínios.

E como citamos, no início de nossos estudos, Descartes faz toda esta construção lógica para ao final do texto mostrar sua verdadeira intenção, ou seja, provar a existência de Deus.

\begin{abstract}
Entendo pelo nome de Deus certa substância infinita, independente, eterna, imutável, sumamente inteligente e sumamente poderosa e pela qual eu mesmo fui criado e tudo o mais existente, se existe alguma outra coisa. Todas essas coisas são tais que, quanto mais cuidadosamente lhes presto atenção, tanto menos parece que elas possam provir somente de mim. Por isso, do que foi dito deve-se concluir que Deus existe necessariamente. (Meditações sobre a Filosofia Primeira, p. 91).
\end{abstract}

Como pudemos ver, o estilo de escrita e de construção da argumentação cartesiana é bem simples e fluida, fazendo com que cheguemos às conclusões que ele expressa juntamente com ele no texto. Isto após o estilo rebuscado do que havia antes dele e do que virá depois é bem impressionante.

Paul Strathern (1997) nos dá uma pista para a utilização de argumentos de Anselmo, de Tomás de Aquino e Francisco Sanches no texto cartesiano:

\begin{abstract}
(Descartes) chega ao ponto de provar a existência de Deus - com argumentos usados anteriormente por santo Anselmo e são Tomás de Aquino mais de quatro séculos antes -, ao que parece para fazer a Igreja se sentir mais à vontade. Apesar de esse processo de dúvida cartesiana não ser original estritamente falando, na época era assim considerado. As dúvidas e a conclusão de santo Agostinho, de semelhança notável, formuladas doze séculos antes, não eram centrais em seu pensamento e tinham sido totalmente ignoradas. Mais próximo da época de Descartes, no entanto, e de maneira mais interessante, o filósofo português Francisco Sanches, propusera, quase com exatidão, o mesmo roteiro abrangente de dúvidas em seu surpreendente tratado Quod nihil scitur (Por que nada se pode saber), publicado em 1581.
\end{abstract}

\section{CONCLUSÃO}


Há muitos pontos no trabalho de Renè Descartes que dão a impressão de que este autor usaria sim argumentos de outros autores, sendo que três deles foram destacados aqui no presente trabalho. No entanto, como observamos, nada vem do nada, e para um filósofo do Renascimento seria impossível não conhecer os clássicos de Anselmo e de Tomás de Aquino. E em relação aos textos de Francisco Sanches, que viveu na França e teve um certo destaque na filosofia europeia de sua época, é razoável pensar que se seus argumentos ainda são bons hoje deveriam ter sido muito tentadores para Descartes.

O importante, em relação a Descartes, parece ser não se ele revelou ou não suas influências, mas sim que alguém teria que inaugurar a modernidade na filosofia, e sabemos hoje que foi Descartes que o fez. Nos tirou do pensamento da Idade Média e nos trouxe pensamentos e argumentos, que mesmo não sendo cem por cento dele, são muito interessantes e até hoje dão muito o que falar, inclusive este trabalho.

Quanto ao fato de que suas Meditações terem o intuito de provar a existência de Deus, vimos que os demais autores fizeram o mesmo, o que parece que era uma espécie de necessidade, uma moda, da filosofia medieval e do início da modernidade. Afinal eles eram cristãos, e a religião tinha mais peso em suas vidas do que tem nas nossas atualmente. E o importante é que Descartes é mais conhecido por seu cogito, o que mostra a parte mais importante de seu trabalho.

Outro ponto a salientar, que vimos neste trabalho, é que mesmo se Descartes utilizou de argumentos dos autores apontados no texto, ou de trabalhos de demais autores, uma coisa é certa, ele não parou onde os demais pararam, ele foi muito além, e deve ser aí que devemos dar os créditos a que ele tem direito, e é aí que me reconcilio com a visão que tinha dele antes de questionar sua genialidade.

\section{BIBLIOGRAFIA}

ANSELMO, S. Proslogion seu alloquium de dei existentia. Covilhã. Ed. Lusosofia. 2008.

ARAúJo, G. P. R. A prova da existência de Deus em Anselmo e Tomás de Aquino. Mariana. Faculdade Arquidiocesana de Mariana. 2013.

RUSSELL, B. Historia da filosofia ocidental. São Paulo. Companhia Editora Nacional. 1957. 
COTTINGHAM, J. Dicionário Descartes. Rio de Janeiro. Ed. Jorge Zahar. 1995.

DESCARTES, R. Meditações sobre filosofia primeira. Edição bilíngue. Tradutor: Fausto Castilho. Ed. Unicamp. 2013.

FREITAS, M. B. C. O Ser e os Seres. Itinerários Filosóficos, 2 volS., Editorial Verbo, Lisboa, 2004.

LAUAND, J. Tomás de Aquino, Anselmo de Canterbury e a crítica da razão teológica. Maringá. Acta Scientiarum. Education. Editora da Universidade Estadual de Maringá-Eduem. 2010.

NUNES, Á. O racionalismo de Descartes. Disponível em: <http://criticanarede.com/his_descartes.html>. Acesso em: 26 de ago. 2017.

PINTO, P. R. M. As ideias filosóficas de Francisco Sanches. Sképsis, ano iii, $\mathrm{n}^{\mathrm{o}}$ 5, 2010.

SALES, E. O Conceito de Gênio na Filosofia. Cadernos Paranoá, No 2, 2006, in http://periodicos.unb.br/index.php/paranoa/article/view/15231. Acesso em: 25 de set. 2017.

SANCHES, F. Quod nihil Scitur. Cambridge University Press. 1988.

SOARES, A. J. A prova ontológica em Anselmo, Tomás de Aquino e em Descartes. Revista Direito e Liberdade - ESMARN - Mossoró - V. 2, N. 1, p. 21 - 32 - jan/jun 2006.

STRATHERN, P. Darwin e a evolução em 90 minutos. Tradução de Maria Helena Geordane. Jorge Zahar Editor. Rio de Janeiro. 2001.

Descartes em 90 minutos. Filósofos em 90 minutos. Rio de Janeiro. Ed. Jorge Zahar. 1997.

São Tomás de Aquino em 90 minutos. Filósofos em 90 minutos. Rio de Janeiro. Ed. Jorge Zahar. 1999.

TAVARES, S. Francisco Sanches e o problema da certeza. Actas del Primer Congreso Nacional de Filosofía, Mendoza, Argentina, marzo-abril, tomo 3, 1949.

WESTFALL, R. S. A vida de Isaac Newton. Tradução de Vera Ribeiro. Editora Nova Fronteira. Rio de Janeiro. 1995. 